\title{
Can Telematics Improve Mobility of the Elderly?
}

\author{
Berthold Färber PhD \\ Human Factors Institute, University of the Bundeswehr, Munich \\ D 85577 Neubiberg, Germany \\ e-mail: berthold.faerber@unibw-muenchen.de
}

\begin{abstract}
B. Färber, Can Telematics Improve Mobility of the Elderly, Gerontechnology 2002; 1(4): 287 - 290. Telematics systems are analysed with respect to four problem areas of older drivers: movability, vision, fast processing of complex information, and understanding complex systems. It is concluded that some of the systems are of principal value to improve mobility of the elderly. However, the increasing number of complex systems causes problems for older drivers. Moreover, development of telematics is too heavily driven by technology instead of by the needs of elder drivers. There remains a need for the creation of easy-to-use Human Machine Interfaces.
\end{abstract}

Keywords: Telematics, Older Drivers, Human-Machine-Interface

ITelematics, an acronym combining telecommunication and informatics, covers a variety of systems to be implemented in modern cars. Telematics in the narrow sense comprises systems with an onboard unit in the car and a connection to a host computer or service provider. In a broader sense, telematics describes an increasing number of driver assistance systems, partly realised as standalone systems and partly needing road infrastructure.

Accident analysis and self reports give a quite long list of deficits of elder drivers ${ }^{1-2}$. The development of telematic systems, on the other hand, is mainly driven by technology and not by the main deficits of this user group. Thus, none of these systems is specifically designed for elder people. Nevertheless, they can principally be of some value for this user group. Evaluation of possible impacts is performed with respect to the needs and deficits of this driver group. Because experimental results focusing on elder drivers are quite rare, the evaluation is based on an expert's view as well as an expert evaluation of researchers in the fields of telematics industry and traffic safety.

\section{EVALUATION OF TELEMATICS SYSTEMS}

The list of problems of elder drivers can be categorised into four problem-groups: movability, vision, fast processing of complex information, and understanding complex systems. What should telematics achieve to solve or at least to reduce these problems?

\section{Movability}

The decrease of movability with growing age raises problems in narrow parking lots and reverse driving. Park distance control with optical and acoustical warning is an excellent means of coping with this deficit. Forward, backward, and lateral ultrasonic sensors are able to exactly measure the distance and inform the driver. Ayala et al. $^{3}$ demonstrated among more than 100 subjects in the age of $65-86$ years an increase in correct parking maneuvers from 58\% (without parking aid) to 95\% (with parking aid).

Overtaking, as well as left and right turning, necessitates head movements to overcome 


\section{Telematics and Mobility}

the blind spot problem of mirrors. Research activities to solve this problem by technological means are twofold: A theoretically 'perfect' solution is car-to-car / car-to-pedestrian communication. Every traffic participant broadcasts a signal which is received and interpreted by each car in the vicinity. This technology would not only solve traffic safety problems of the elderly as car drivers, but also as pedestrians. However, this development would require extensive standardisation, and it would take 15 years before all cars were equipped. The more realistic approach uses cameras, additionally or instead of the mirrors. Collision paths of objects near the car are processed, and warning signals are displayed by red or green lights in the mirror or as video images. These systems are under research and have potential to assist older drivers. Figure 1 shows an experimental vehicle with rear camera vision and rear warning display next to the driver.

\section{Vision}

Vision deficits of elder drivers include reduced visual acuity, prolonged accommodation and adaptation times, reduced peripheral vision and increased glare sensitivity during night driving. Visual acuity and accommodation problems are not the primary focus of telematic systems but can be solved by means of well adapted spectacles and ergon- omically designed displays. Förster ${ }^{4}$ has calculated that about $35 \%$ of drivers over 70 years are unable to drive at night. Ling Suen and Mitchell ${ }^{5}$ argue that enhanced vision systems would especially improve safety of older or handicapped people. So, why don't we have better night driving aids? The answer is quite simple. Effective enhancement of night vision cannot be performed by increasing light density of headlamps of cars, because this would entail increased glarealready a problem for the elderly in particular. Technology using infrared light and image processing in combination with a virtual image is the only way to really solve vision problems associated with night driving. Infrared cameras and image processing are current technologies. The difficulty lies in the human-machine-interface. All attempts to display the virtual image of traffic scenes on an additional video screen have proved to be insufficient. Only if the virtual image covers the whole windshield of the driver will he or she get a realistic and valuable image for regulating driving behavior. In addition, a prerequisite is the measurement and compensation of head movements of the driver. Unfortunately, no reliable technical solution for the Human Machine Interface (HMI) is currently available; therefore, this problem of older drivers will persist.
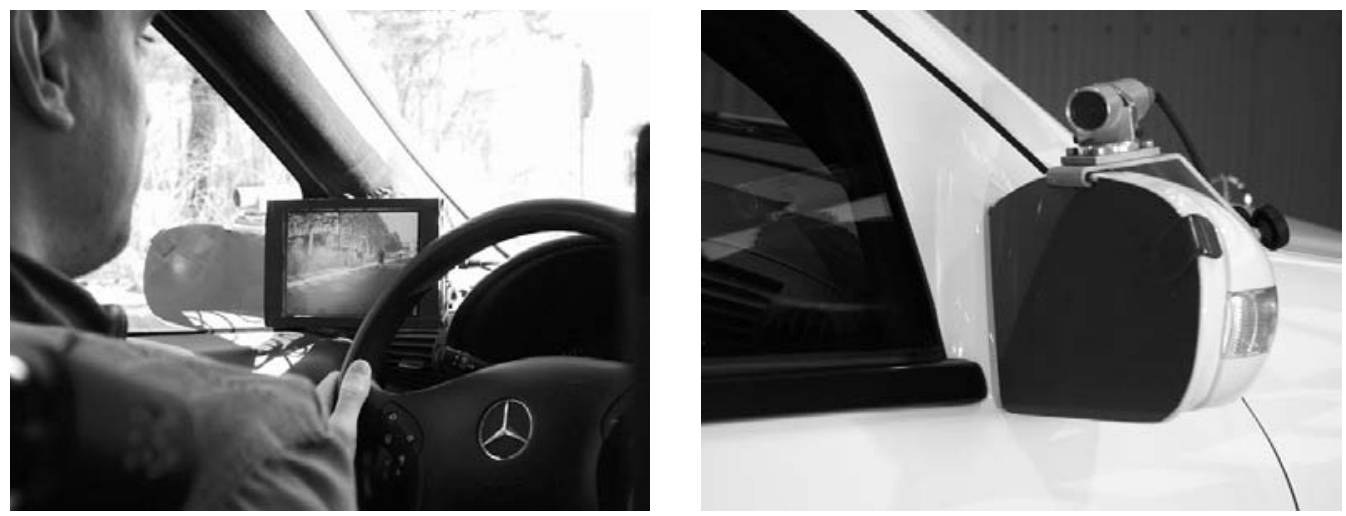

Figure 1: Experimental vehicle (Human Factors Institute, UniBw, Munich) to test improved rear vision 


\section{Fast processing of complex information}

For highly trained, habitualised behavior like steering or braking in conventional situations, reduced information processing speed is a minor problem. Typically, complex situations causing problems to elder drivers are turning maneuvers at crossings and roundabouts and sharp braking actions. The main deficit of elder drivers is not the longer (mainly motor) reaction time to simple cues but the longer decision time. Prolonged decision times at unforeseen braking situations can be partly compensated by brake assistants. The first generation of such a device measures pedal activation speed, predicts the desired deceleration rate of the driver and adapts deceleration rate of the car. The next generation of refinements will integrate relative speed and distance to other traffic participants into the calculation, in order to improve brake adaptation. The long term goal of automobile engineers is the integration of more and more situational information to support the driver during complex maneuvering actions ${ }^{6-9}$.

The above examples illustrate the principal positive contribution of telematic systems to improve individual mobility of elder people. Other systems not explained here in detail, such as navigation systems or emergency calls transmitting the actual position of the car, are doubtlessly helpful devices to improve subjective and objective safety and thus mobility of elder drivers. For a more detailed discussion see Färber ${ }^{10}$.

\section{PROBLEM AREAS AND RESEARCH ACTIVITIES FOR THE FUTURE}

Besides telematics systems directly related to driving, many other items like car telephone, e-mail and internet connection, hotel or restaurant guides, ticket reservation services, etc., will become standard equipment in modern cars. Even if a driver doesn't want or use these features, the high-end car will have them as standard configurations, due to marketing reasons. To handle the many functions (useful ones and less useful ones), multifunctional display and control units are prerequisite. Car manufacturers use different approaches for the layout, but they all face similar challenges. Too many features (e.g. radio, climate, navigation-system, telephone) with totally different forms of internal logic must be integrated into one system with a common menu structure. Prominent examples of such systems are the iDrive of BMW or the Comand of DaimlerChrysler (Figure 2).

Many automobile customers - especially older ones - are overloaded by the increasing number of functionalities. The danger of such overload is that this user group will
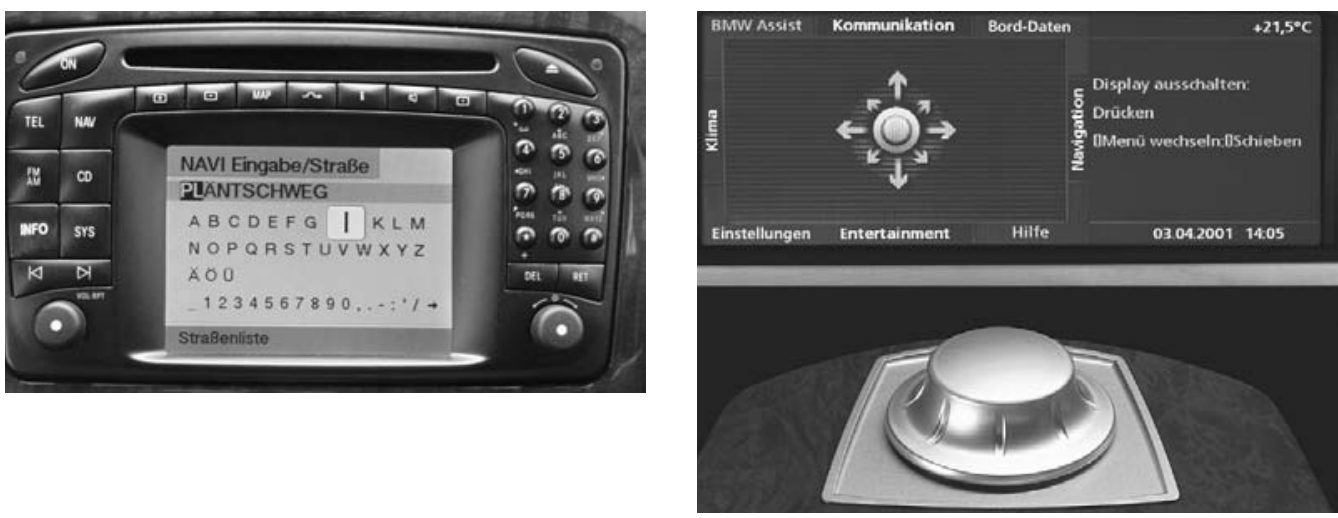

Figure 2: Multifunctional display and control units: Comand (DaimlerChrysler) and iDrive $(B M W)$ 


\section{Telematics and Mobility}

become disconnected from technological development that can be quite helpful for the maintenance of mobility.

Development should therefore go along two lines:

First, information management is necessary to avoid too many pieces of information being displayed at the same time. Information management must take into account the actual driving situation as well as driver experience and long-term and shortterm driver conditions ${ }^{11}$.

Second, the user must be integrated into the design process. The integration of users in the design process is a longstanding but seldom fulfilled demand. The integration of elder users in the design and development process would have an eminent advantage for traffic safety as a whole. Systems that can be handled without problems by older persons can be used with minimal distraction by all other driver groups. To bring it to one statement: Elder drivers should be the test criterion for the usability and safety of telematics systems.

\section{References}

1. Kaiser HJ, Oswald WD. Autofahren im Alter eine Literaturanalyse.[Car Driving in the Old Age - a Literature Analysis]. Zeitschrift für Gerontopsychologie und -psychiatrie 2000;13(3/4):131-170

2. Brouwer WH, Rothengatter JA, Wolffelaar PC van. Older Drivers and Road Traffic Informatics. In: Bouma H, Graafmanns JAM, editors, Gerontechnology. Amsterdam: IOS Press; 1992; pp 317 - 328

3. Ayala B, Barham P, Oxley P. Advanced transport telematics (ATT) and elderly drivers: benefits and safety implications. In: Nwagboso CO, editor, Road Vehicle Automation II. Toward Systems Integration. Proceedings of the 2 nd International
Conference on Road Vehicle Automation. 11th - 13th Sept. 1995. Chichester: John Wiley; 1995; pp pp 568-577

4. Förster HJ. The Automobile, an Elixir of Life for Elder People. In: Verein Deutscher Ingenieure, editors, The driver in the 21st Century. Düsseldorf: VDI; 2001; pp 115-152

5. Ling Suen S, Mitchell C. Application of intelligent transport systems to enhance vehicle safety for elderly and disabled travellers. In: Abstracts of the 16th ESV Conference of the NHTSA, Windsor, Canada, June 1-4, 1998. http: // www-nrd.nhtsa.dot.gov/esv/esvweb2.htp, 98-S2-O-03; 1998

6. Bloomfield AJ, Levitan B L, Grant AA, Brown AT, Hankey AJ. Driving performance after an extended period of travel in an automated highway system. FHWA/RD-98/051.

Washington, DC: Department of Transportation, Federal Highway Administration; 1998

7. Dingus TA, McGehee DV, Manakkal N, Jahns SK, Carne C, Hankey JM. Human factors field evaluation of automotive headway maintenance / collision warning devices. Human Factors 1997;39(2):216-229

8. Perel M. Helping older drivers benefit from collision avoidance technologies. In: Abstracts of the 16th ESV Conference of the NHTSA, Windsor, Canada, June 1-4, 1998. http: // www-nrd.nhtsa.dot.gov/esv/esvweb2.htp, 98-S2-O -11; 1998

9. Shladover SE. Progressive development steps leading toward an automated highway system. Transportation Research Record 2000;1727(00-0835):154-161

10. Färber B. Micro Intervention: Assistive Devices, Telematics, Person $\times$ Environment Interactions. In: Schaie KW, Wahl HW, Mollenkopf $\mathrm{H}$, Oswald $\mathrm{F}$, editors, Aging in the Community: Living Arrangements and Mobility. New York: Springer; 2002; In press

11. Färber B, Färber BA, Schmitt J. Informationsmanagement für Fahrerassistenz-Systeme mittels Prädiktion der Fahrerbelastung. [Information management for Driver assistance Systems by means of prediction of driver work load].

Düsseldorf: VDI; 2002 